\title{
Blunt Right ICA Biffle Grade IV Injury in a Case of Polytrauma: Successfully Managed by Decompressive Craniectomy.
}

\author{
*DS Asif ${ }^{1}$, SM Ridwan ${ }^{2}$, AMR Sattar $^{3}$, SSK Gaddam ${ }^{4}$ \\ $1 * D r$. Dewan Shamsul Asif, associate professor, department of neurosurgery, Anwer khan modern medical college, Dhaka, \\ ${ }^{2}$ Dr. Sharif Mohammad Ridwan, Medical officer, department of neurosurgery, Square Hospitals Limited Dhaka, \\ ${ }^{3}$ Dr. AM Rejaus Satter, Associate consultant, department of neurosurgery, Square Hospitals Limited Dhaka, \\ ${ }^{4}$ Dr. Samson S.K. Gaddam, Consultant, Neurosurgery department, Square Hospitals Limited Dhaka,
}

*Corresponding author

Date of submission: 09.07.2016 Date of acceptance: 17.10.2016

\begin{abstract}
Traumatic brain injury (TBI) is common in our country. In our daily practice we are successfully managing TBI. But in some cases patient clinical conditions do not correlate with neuroimaging specially CT scan of brain. These injuries are generally missed due to lack of awareness, paucity of findings in the initial CT brain, and in some cases due to delayed clinical manifestation. For more effective and appropriate management especially blunt cerebrovascular injury we are reporting this. Moreover in RTA poly trauma make our choice of treatment more difficult but rational approach can safe a patient as did in our case.
\end{abstract}

\section{Introduction}

Blunt cerebrovascular injury is defined as a vertebral or carotid arterial structural wall injury resulting from nonpenetrating trauma. ${ }^{1}$ Complete traumatic occlusion is more prone to ischaemic stroke, reported in 13\%-24\% of vertebral artery (VA) and $50 \%-90 \%$ of internal carotid artery (ICA)injuries. ${ }^{2-4}$ These injuries are generally missed due to lack of awareness, paucity of findings in the initial CT brain, and in some cases due to delayed clinical manifestation. We report a 43 year lady with severe head injury and pupillary asymmetry, due to Biffle grade IV right ICA injury complicated by a large right MCA infarct. She was successfully managed with decompressive craniectomy.

\section{Case Report}

A 43 year old presented with hypovolemic shock with low GCS and left hemiplegia. There were laceration injuries on the right side of the chin, redness and swelling over the right side of neck, lacerations in front of the right tragus. A vulval haematoma was also noted. CT scan of brain showed left temporal haemorrhagic contusion, a large right MCA territory infarction with mass effect and significant midline shift. CT chest and abdomen revealed right side haemopneumothorax , comminuted fracture of right clavicle, and fracture of right 2,3,4,5,6 and 7 ribs and fractures of superior and inferior rami of right pubis and also both the ala of sacrum respectively. After inserting a right ICT she underwent an emergency right fronto-tempero-parietal decompressive craniectomy. On first post-operative day CT angiogram of neck and cerebral vessels showed non-opacifiction of right ICA up to cavernous sinus starting from proximal $1.5 \mathrm{~cm}$ of carotid bifurcation and with a good collateral circulation from left ICA across the circle of Willis opacifying the supraclinoid right ICA. Due to the risk of ICH, presence of hypovolemic shock, hemopneumothorax\& pelvis fractures, anti-platelet or anticoagulant therapy was not instituted; instead she was started on a vasodilator (Cilostazol $50 \mathrm{mg}$ bd). After a stormy ICU course she eventually improved in her neurological state to GCS 15/15 with residual left sided hemiparesis. 


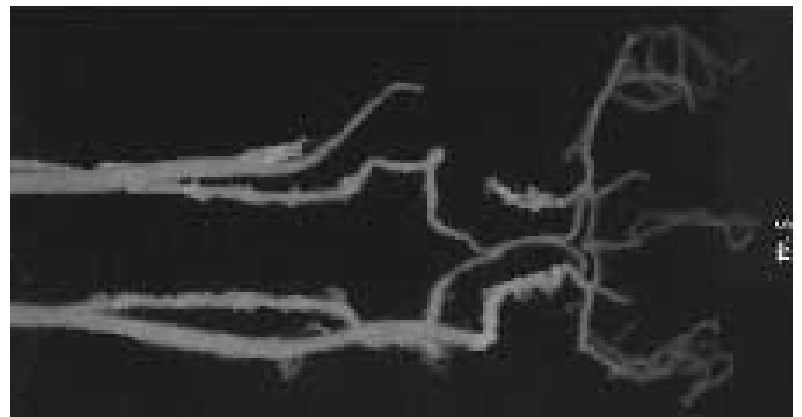

Fig-1

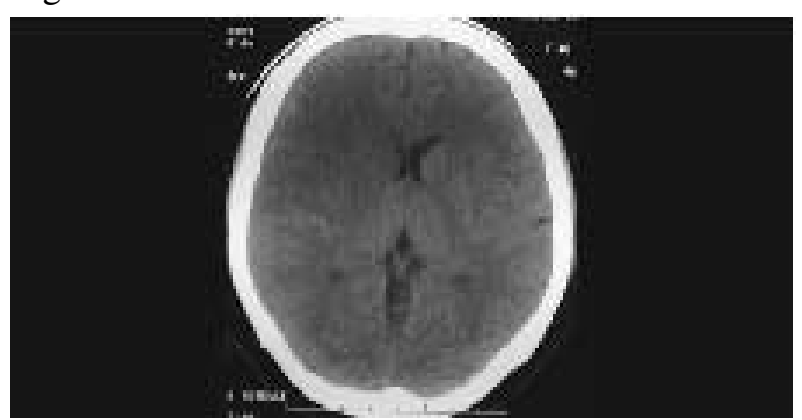

Fig-2

\section{Discussion}

Blunt cervical carotid artery injuries are less commonly seen than penetrating injuries.(5) Rubio, et al.,(6)described 72 patients with carotid artery trauma of which only two sustained non-penetrating injury. Blunt injuries are usually caused by motorvehicle accidents; however various other causes like fist fights, falls, blows to the neck or head from various objects, carotid artery compression, hanging by the neck, local surgical procedures, or manipulative therapy, carotid artery dissection during angiography have also been reported.(7) Neurovascular injury is more common in a fracture which involve central skull base.(8) Complete arterial occlusion (Biffl Grade IV) carries the highest risk of stroke and neurological morbidity.(24) Thromboembolism and hemodynamic insufficiency are the two potential mechanisms of BCI-related stroke in most cases.(9) In our case the complete MCA infarct was probably due to Biffle grade IV right carotid artery injury, potentiated by severe hypotensive shock due to polytrauma.

BCI may present with no symptoms or may result in severe neurological deficit. Several studies described BCI along with other injuries.(10-12)
These patterns of injuries on radiological imaging should heighten the suspicion of a BCI. There is convincing evidence that a significant number of BCI -related strokes occur before any treatment can be initiated. However, this leads to the conclusion that patients with $\mathrm{BCI}$ diagnosed by screening in the absence of BCI -related stroke symptoms will likely have a benign course and are unlikely to develop a delayed ischemic event.(9) Potential risks for mortality or neurologic impairment are shock at the time of admission (systolic blood pressure $<90$ $\mathrm{mmHg}$ ), old age, major neurologic deficit at the time of diagnosis, carotid thrombosis, injury Severity Score, and associated brain injury. (13) Our patient had all these potential risk factors for mortality except for age. However early fluid resuscitation with good collateral circulation, intensive ICU management and early decompressive craniectomy have resulted in a good outcome in our case.

The gold standard for the diagnosis of BCI is fourvessel biplanar cerebral DSA; however, it is invasive and resource-intensive. For the ready availability, ubiquitous utilization in trauma patients, and rapidly advancing technology there has been always a great deal of enthusiasm for CTA.(14)

Management of BCI involves either resection with grafting, or extracranial-intracranial bypass and anticoagulation approach is systemic heparin therapy.(13) But each has its drawbacks and it depends entirely upon the physical condition of the patient. There is no general rule which can be applied for the management of all patients with BCI. In the presence of other cerebral or visceral trauma, anticoagulant therapy may not be possible or may be contraindicated, and at the very least its institution may be a difficult decision.(10) Rate of haemorrhagic complication is high with heparin therapy though traditionally may be popular. $(13,15-$ 17) It is reported that $36 \%$ of patients with BCI are not candidates for intravenous anticoagulation because of systemic traumatic injuries. $(4,18)$ In patients with complete ICA occlusion and stroke, rapid assessment of collateral circulation on $\mathrm{CT}$ angiography may help determine future 
management.(19)

\section{Conclusion}

Blunt carotid artery injuries are rare and there may be a delay in the diagnosis especially in cases of poly-trauma. A high index of suspicion is required and a CT angiogram or DSA should be done to screen or diagnose these cases. The surgical, medical or combined management of these patients should be tailored to the individual cases especially in poly-trauma. Decompressive craniectomy have a role in managing BCI patients with clinical and radiological features of large infarct and raised intracranial pressure.

\section{Conflict of Interest: none}

\section{References}

1. Fusco MR, Harrigan MR. Cerebrovascular dissections: a review. Part II: blunt cerebrovascular injury. Neurosurgery. 2011;68(2):517-30; discussion 30. Epub 2010/12/08.

2. Biffl WL, Moore EE, Elliott JP, Ray C, Offner PJ, Franciose RJ, et al. The devastating potential of blunt vertebral arterial injuries. Annals of surgery. 2000;231(5):672-81. Epub 2000/04/18.

3. Biffl WL, Moore EE, Offner PJ, Brega KE, Franciose RJ, Burch JM. Blunt carotid arterial injuries: implications of a new grading scale. The Journal of trauma. 1999;47(5):845-53. Epub 1999/11/24.

4. Stein DM, Boswell S, Sliker CW, Lui FY, Scalea TM. Blunt cerebrovascular injuries: does treatment always matter? The Journal of trauma. 2009;66(1):132-43; discussion 43-4. Epub 2009/01/10.

5. Krajewski LP, Hertzer NR. Blunt carotid artery trauma: report of two cases and review of the literature. Annals of surgery. 1980;191(3):341-6. Epub 1980/03/01.

6. Rubio PA, Reul GJ, Jr., Beall AC, Jr., Jordan GL, Jr., DeBakey ME. Acute carotid artery injury: 25 years' experience. The Journal of trauma. 1974;14(11):96773. Epub 1974/11/01.

7. Yamada S, Kindt GW, Youmans JR. Carotid artery occlusion due to nonpenetrating injury. The Journal of trauma. 1967;7(3):333-42. Epub 1967/05/01.

8. Feiz-Erfan I, Horn EM, Theodore N, Zabramski JM, Klopfenstein JD, Lekovic GP, et al. Incidence and pattern of direct blunt neurovascular injury associated with trauma to the skull base. Journal of neurosurgery. 2007;107(2):364-9. Epub 2007/08/19.
9. Griessenauer CJ, Fleming JB, Richards BF, Cava LP, Cure JK, Younan DS, et al. Timing and mechanism of ischemic stroke due to extracranial blunt traumatic cerebrovascular injury. Journal of neurosurgery. 2013;118(2):397-404. Epub 2012/12/12.

10. Mokri B, Piepgras DG, Houser OW. Traumatic dissections of the extracranial internal carotid artery. Journal of neurosurgery. 1988;68(2):189-97. Epub 1988/02/01.

11. Morgan MK, Besser M, Johnston I, Chaseling R. Intracranial carotid artery injury in closed head trauma. Journal of neurosurgery. 1987;66(2):192-7. Epub 1987/02/01.

12. Welling RE, Saul TG, Tew JM, Jr., Tomsick TA, Kremchek TE, Bellamy MJ. Management of blunt injury to the internal carotid artery. The Journal of trauma. 1987;27(11):1221-6. Epub 1987/11/01.

13. Fabian TC, Patton JH, Jr., Croce MA, Minard G, Kudsk KA, Pritchard FE. Blunt carotid injury. Importance of early diagnosis and anticoagulant therapy. Annals of surgery. 1996;223(5):513-22; discussion 22-5. Epub 1996/05/01.

14. Biffl WL, Egglin T, Benedetto B, Gibbs F, Cioffi WG. Sixteen-slice computed tomographic angiography is a reliable noninvasive screening test for clinically significant blunt cerebrovascular injuries. The Journal of trauma. 2006;60(4):745-51; discussion 51-2. Epub 2006/04/14.

15. Eachempati SR, Vaslef SN, Sebastian MW, Reed RL, 2nd. Blunt vascular injuries of the head and neck: is heparinization necessary? The Journal of trauma. 1998;45(6):997-1004. Epub 1998/12/29.

16. Miller PR, Fabian TC, Bee TK, Timmons S, Chamsuddin A, Finkle R, et al. Blunt cerebrovascular injuries: diagnosis and treatment. The Journal of trauma. 2001;51(2):279-85; discussion 85-6. Epub 2001/08/09.

17. Miller PR, Fabian TC, Croce MA, Cagiannos C, Williams JS, Vang M, et al. Prospective screening for blunt cerebrovascular injuries: analysis of diagnostic modalities and outcomes. Annals of surgery. 2002;236(3):386-93; discussion 93-5. Epub $2002 / 08 / 23$.

18. Wahl WL, Brandt MM, Thompson BG, Taheri PA, Greenfield LJ. Antiplatelet therapy: an alternative to heparin for blunt carotid injury. The Journal of trauma. 2002;52(5):896-901. Epub 2002/05/04.

19. Morton RP, Hanak BW, Levitt MR, Fink KR, Peterson $\mathrm{EC}$, Vilela MD, et al. Blunt traumatic occlusion of the internal carotid and vertebral arteries. Journal of neurosurgery. 2014;120(6):1446-50. Epub 2014/04/01. 